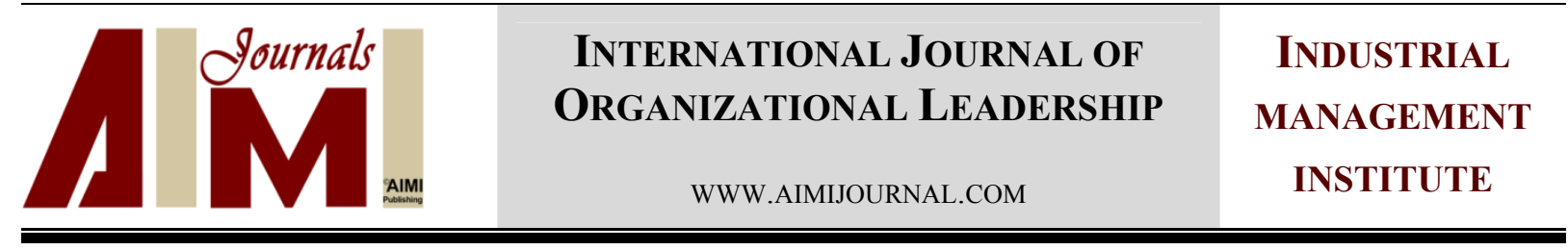

\title{
Human resource practices and knowledge sharing: The moderating role of trust
}

\author{
Uzma Pervaiz', Muhammad Imran ${ }^{2 *}$, Qudsia Arshad ${ }^{3}$, Rabia Haq ${ }^{4}$, Mah-a-Mobeen ${ }^{5}$, \\ Muhammad Kamran Khan ${ }^{6}$ \\ 1,3,4,5 Department of Management Sciences, COMSATS Institute of Information Technology, Islamabad, \\ Pakistan \\ ${ }^{2}$ Department of Management Sciences, COMSATS Institute of Information Technology, Vehari, Pakistan \\ ${ }^{6}$ Gomal University, Dera Ismail Khan, Pakistan
}

\begin{abstract}
Keywords:

Human Resource

Management, Knowledge

Sharing, Performance

Appraisals,

Compensation, Training.

Received

3 November 2015

Received in revised form

20 January 2016

Accepted

28 January 2016

Correspondence:

imran@ciitvehari.edu.pk

HRM is considered as a backbone for successful organizations and knowledge sharing plays a vital role for an organization to success globally. The purpose of the study is to understand the factors that contribute to knowledge sharing in an organization. This study explains how the effective training, fair compensation and performance appraisal affects the knowledge sharing. The impact of trust on relationship of HR practices and knowledge sharing is also examined. The study empirically analyzes the relationship between HR practices and the knowledge sharing and the strong effect of trust. The correlations, simple and multiple regression tests apply to data. Findings provide evidence of a positive and significant relationship between the HR practices and knowledge sharing in the presence of trust. An organization that wants to enhance the creation, innovation and development of knowledge sharing in organization must pay attention to its HRM practices and on trust worthy environment.

In competitive business environment, knowledge management is considered as an essential organizational resource that provides sustainable competitive advantage. The recognition of knowledge management, as a major resource used by today's organizations, identifies the need of an effective and smooth process of creation, evaluation, distribution, and use of knowledge at individual and collective level. Knowledge sharing gives power to employees and organizations to act and make timely and necessary decisions that are valuable for employees
\end{abstract}


and firms to succeed in determining economy and it enables firms to remain profitable in business competitive environment.

According to Edvardsson (2008) knowledge-oriented human recourse practices can improve firms' knowledge sharing processes through two different ways. First, firms can use such human resource management (HRM) practices which can provide a foundation for acquiring and encouraging firms' employees. Second, firms can use such sorts of HRM practices for building an organizational culture that support the knowledge capture, transfer, and use. Chen and Huang (2011) stated that HRM practices and policies are the key sources by which organizations can influence on the individuals' behaviors, attitudes, and skills. Trust in the workplace is encouragement and freedom that employees can put to their creativity and passion to work. In this fast-growing environment, where flow of information resources or knowledge transfer processes are considered as competitive advantage, trust plays an important role mostly in the transfer of knowledge or flow of information. Trust would modulate the relationship between HRM practices and employees' knowledge sharing. In particular, it provides evidence that employee commitment moderates the relationship between HRM practices and knowledge sharing. This new proposed relationship could enhance employees' abilities and motivation to learn and create a knowledge culture that will foster the concept of sharing.

\section{The Literature Review}

Ipe (2003) stated that if an organization wants to be successful, it must capture significant part of knowledge which is growing continuously and then it must be able to utilize of this intellectual asset by making this easily available to all at every level of the organization. Knowledge sharing is considered as a voluntary act, in which employees are encouraged, trained, and rewarded to share knowledge (Collins \& Smith, 2009). Pareek and Purohit (2010) argued that effective training programs develop employees' skills and knowledge that promote them to the highest levels of the organization.

The training programs provide platform for employees to interact; therefore, they will provide advancement opportunities contribute to creating knowledge sharing environment (Grimshaw \& Miozzo, 2009). According to congruence approach, if an organization applies internally consistent human resource practices like training that would align and reinforce each other, the impact of training will increase trust which would lead to intervention between employees of an organization and external business environment (Currie \& Kerrin, 2010).

A well-structured compensation plan related to the performance appraisal which measures the knowledge sharing will positively influence on knowledge sharing (Lopez-Cabrales, PérezLuño, \& Cabrera, 2009). Compensation techniques which reward employees' knowledge creating and transferring will motivate the employees to share their knowledge with the organization and their coworkers. Importantly, the incentive compensation related to knowledge sharing encourages the experimentation and learning in employees (Jimenez \& Valle, 2013). In the interim, incentives should be based on overall firm performance, common goals, and shared vision. It means that all employees having the same goals gain the same knowledge. Also, they can also foster the process of sharing learning knowledge and insights (N.C. Liu \& M. S. Liu, 2011). 
According to Selvarajan and Cloninger (2012), organizations should use systematic performance appraisals which specifically related to knowledge sharing and include performance feedback. Jimenez and Valle (2013) stated that such kinds of feedback motivate the employees to share their knowledge within their firms which can also be included in evaluation process. Performance appraisals should be based on long term results in the context of original performance in order to improve the operational performance because acquisition and distribution of new knowledge take time so that it can be translated into results and activities (Currie \& Kerin, 2010). If organizations want to engage their employees in knowledge sharing process, they are needed to employ more sophisticated performance appraisals systems which measure and value the specific contributions of employees in knowledge sharing (Camelo-Ordaz, Garcia-Cruz, Sousa-Ginel, \& Valle-Cabrera, 2011).

In order to develop and share new or existing knowledge, providing security through an atmosphere of trust seems to be essential to encourage experimentation, risk taking, and innovation (Allameh, Zare, \& Davoodi, 2011). Trust has been defined as an expectation that arises within a community of regular, honest, and cooperative behavior, based on commonly shared norms. Trust among people is associated with professional relationships rather than individual relationships (Saeed, Ahmad, Anis-Ul-Haque, \& Chaudhry, 2010).

Interpersonal trust facilitates effective knowledge management process through removing knowledge sharing barriers in an organization (Holste \& Fields, 2010). Nonaka (1994) stated that trust builds a healthy atmosphere for knowledge sharing and acts as a moderator. Management of formal encouragement is considered as a base for knowledge sharing through which the tacit and explicit knowledge is generated and shared among employees. According to Hassan, Toylan, Semerciöz, and Aksel (2012), human resource practices related to career development and the rewards system are considered more important for knowledge sharing. If the human resource practitioners pay attention on knowledge management processes specifically in knowledge creation and sharing in an organization, they can promote the trust worthy environment in which the knowledge can be shared effectively (Renzl, 2008).

According to Staples and Webster (2008), trust plays a vital role in knowledge sharing process among employees when effective human resource practices are implemented in organization. The presence of high trust among employees results in human resource practices influence on knowledge sharing effectively. Organizations should build trust among themselves and their employees and promise to fulfill their expectations of knowledge sharing. Trust is therefore a key dimension in strengthening the power of an ideal human resource system to share knowledge (Hall \& Goody, 2007).

\section{Research Hypotheses}

In line with the discussion above, the following research hypotheses were formulated:

$\mathbf{H}_{1}$ : The use of effectual training programs would enhance the sharing of knowledge.

$\mathbf{H}_{2}$ : Employees will share knowledge frequently because of the fair compensation techniques.

$\mathbf{H}_{3}$ : Equitable and effective performance appraisals would enable the employees to share their knowledge.

$\mathbf{H}_{4}$ : Trust would strengthen the relationship between training and knowledge sharing. 
H5: The relationship of compensation and knowledge sharing would be stronger in presence of trust as moderator.

H6: The relationship between performance appraisal and knowledge sharing would be enhanced by trust.

\section{Method}

Current study focuses on theories and concepts and evaluates the relationship between training, compensation, performance appraisal, trust, and knowledge sharing. This study engages in hypotheses testing and explains the relationship between the variables. A co-relational study is conducted in the natural environment of the organization with minimum interference by the researcher with the normal flow of work. The statistical population of this study consisted of employees in service sectors from managerial and operational levels in Rawalpindi and Islamabad locality. The reason for selecting the service sectors for this study is that the learning organizations are more dynamic and risk taking than manufacturing organizations. In addition, such kinds of organizations value and prefer the knowledge sharing because they know that it is the best way to inspire innovation.

In this study, the main instrument of this study was a questionnaire. All its items are measured on a 5-point Likert scales ranging from strongly disagree to strongly agree. All items in this study were adopted from different related instruments used in previous studies. First, Goodman and Darr (2000) instrument was used to measure knowledge sharing. The reliability coefficient alpha for this instrument was 0.72 . According to Nunnally (1978), Cronbach's alpha score greater than 0.7 generally was considered as satisfactory level of reliability. Second, the instrument developed by Jimenez and Valle (2013) was used to measure training, compensation, and performance appraisal variables. Cronbach's alphas for training, compensation, and performance appraisals variables were $0.83,0.87$, and 0.88 respectively. Finally, McAllister's instrument (2000) was used to measure trust which its Cronbach's alpha was estimated to be 0.61. According to Yang and Chen (2007) the values higher than 0.6 can also be considered as acceptable value. SPSS statistics version 16 was applied to analyze the data. Regression analysis was used to quantify the association between the variables and attempt to explain the variation in dependent variable using the variation in independent variables.

\section{Data Analysis}

The current researcher applied Multiple Regression analysis to calculate the difference between means or the slop of the relationship between variables which was consistent with previous studies (J. Cohen \& P. Cohen, 1983; Miozo, 2011; Warr, 1990) to verify the moderating role of trust.

Table 1 displays the coefficient correlation between the independent variables including training, compensation, and performance appraisals and dependent variable which is knowledge sharing. Results showed that all the independent variables had a significant positive impact on the dependent variable. The $\mathrm{R}$ squared value (0.56) showed that the overall regression model was a good fit for the data. Furthermore, it showed that 56 per cent change in the knowledge sharing can be reported for the training, compensation, and performance 
appraisals. The given results suggested that the human resource practices positively associated with knowledge sharing. F value (7.9) revealed that the independent variables moderately clarified the variation in the dependant variable with the significant $p$-value $(0.00)$ which was highly significant. Thus, the results of study supported the first three hypotheses of the study.

Table 1

Regression Coefficients for the Trust, Compensation, Performance Appraisals, \& Knowledge Sharing Models

\begin{tabular}{|c|c|c|c|c|c|}
\hline \multirow{2}{*}{ Models } & \multicolumn{2}{|c|}{ Unstandardized Coefficients } & \multirow{2}{*}{$\frac{\text { Standardized Coefficients }}{\beta}$} & \multirow[t]{2}{*}{$\mathrm{t}$} & \multirow[t]{2}{*}{ Sig. } \\
\hline & $\mathrm{B}$ & Std. Error & & & \\
\hline (Constant) & 2.3 & 0.47 & & 4.8 & 0.00 \\
\hline $\mathrm{T}$ & 0.14 & 0.05 & 0.17 & 2.9 & 0.00 \\
\hline $\mathrm{C}$ & 0.57 & 0.05 & 0.44 & 11 & 0.00 \\
\hline PA & 0.44 & 0.09 & 0.29 & 5.0 & 0.00 \\
\hline $\mathrm{R}^{2}=0.56$ & $F=7.9$ & & & & \\
\hline
\end{tabular}

*Note. $\mathrm{KS}=$ Knowledge Sharing; $\mathrm{T}=$ Training; $\mathrm{C}=$ Compensation; $\mathrm{PA}=$ Performance Appraisals.

Consistent with J. Cohen and P. Cohen (1983) Warr (1990), a hierarchical multiple regression analysis was used to test the moderating effect of trust on human resource practices including training, compensation, and performance appraisals and knowledge sharing. Table 2 presents the score of trust as moderator variable and significant $p$-values $(0.00<0.05)$ which showed that trust as moderator variable had a significant effect on the relationship of training and knowledge sharing.

Table 2

Models Summary: The Moderating Role of Trust on the Relationship between Training \& Knowledge Sharing

\begin{tabular}{|c|c|c|c|c|c|c|c|c|c|}
\hline \multirow[b]{2}{*}{ Models } & \multirow[b]{2}{*}{$\mathrm{R}$} & \multirow[b]{2}{*}{$\mathrm{R}^{2}$} & \multirow[b]{2}{*}{$\begin{array}{l}\text { Adjusted } \\
\text { R Square }\end{array}$} & \multirow[b]{2}{*}{$\begin{array}{l}\text { Std. Error of } \\
\text { the Estimate }\end{array}$} & \multicolumn{5}{|c|}{ Change Statistics } \\
\hline & & & & & $\begin{array}{c}\mathrm{R}^{2} \\
\text { Change }\end{array}$ & F Change & $\mathrm{df}_{1}$ & $\mathrm{df}_{2}$ & Sig. \\
\hline 1 & $0.11^{\mathrm{a}}$ & 0.01 & 0.01 & 0.80 & 0.03 & 4.12 & 1 & 289 & 0.04 \\
\hline 2 & $0.30^{\mathrm{b}}$ & 0.09 & 0.08 & 0.76 & 0.08 & 25.9 & 1 & 286 & 0.00 \\
\hline 3 & $0.34^{\mathrm{c}}$ & 0.12 & 0.11 & 0.76 & 0.02 & 8.35 & 1 & 285 & 0.00 \\
\hline
\end{tabular}

In Table 2, model 1 illustrates that there was a significant relationship between trust and knowledge sharing using organizational training scores $\left(\mathrm{R}^{2}=.03\right)$. Model 2 shows the significance of the estimated coefficient for knowledge sharing variable because of the training and trust $\left(\mathrm{R}^{2}\right.$ Change $\left.=0.08\right)$, whereas the model 3 states that the training, trust, and interaction term for the two variables have a significant prediction in knowledge sharing $\left(\mathrm{R}^{2}\right.$ change $=$ 0.02). This indicated that there was a significant correlation between incremental variance of knowledge sharing and the dependent variable due to adding interaction term to the regression model. The statistical power of the interaction term for knowledge sharing held the slope coefficient for training depends upon the predictor variable, namely trust. The results revealed that trust as a moderator variable affected the relationship between training and knowledge sharing. Thus, the fourth hypothesis was not rejected.

The results of Table 3 show that trust significantly moderated the positive relationship between compensation and knowledge sharing. Table 3 presents the scores of trust as moderator variable through which researcher easily can analyze the relationship between 
compensation and knowledge sharing in the organization. Table 3 illustrates that $p$-value is less than 0.05 ; therefore, the fifth hypothesis of the study was also confirmed.

Table 3

Model Summary: The Moderating Role of Trust on the Relationship between Compensation \& Knowledge Sharing

\begin{tabular}{cccccccccc}
\hline \multirow{2}{*}{ Models } & $\mathrm{R}$ & \multirow{2}{*}{$\mathrm{R}^{2}$} & \multirow{2}{*}{$\begin{array}{c}\text { Adjusted } \mathrm{R} \\
\text { Square }\end{array}$} & $\begin{array}{c}\text { Std. Error of the } \\
\text { Estimate }\end{array}$ & $\begin{array}{c}\mathrm{R}^{2} \\
\text { Change }\end{array}$ & F Change & $\mathrm{df}_{1}$ & $\mathrm{df}_{2}$ & Sig. \\
\hline 1 & $0.16^{\mathrm{a}}$ & 0.02 & 0.02 & 0.79 & 0.02 & 8.44 & 1 & 289 & 0.00 \\
2 & $0.27^{\mathrm{b}}$ & 0.07 & 0.06 & 0.77 & 0.04 & 14.52 & 1 & 286 & 0.00 \\
3 & $0.30^{\mathrm{c}}$ & 0.09 & 0.08 & 0.77 & 0.01 & 4.71 & 1 & 285 & 0.02 \\
\hline
\end{tabular}

a. Predictors: (Constant), ZC; $\quad$ b. Predictors: (Constant), ZC,ZTR; $\quad$ c. Predictors: (Constant), ZC, ZTR, MODC

In Table 3, the first model presented the existence of significant relationship between compensation and knowledge sharing $\left(\mathrm{R}^{2}\right.$ change $\left.=0.02\right)$. It depicted that compensation has a significant impact on knowledge sharing. The second model showed the significance of the estimated coefficient for knowledge sharing variable $\left(\mathrm{R}^{2}\right.$ change $\left.=0.04\right)$, whereas the third model stated that the compensation, trust, and interaction term for two variables significantly predict knowledge sharing behavior $\left(\mathrm{R}^{2}\right.$ change $\left.=0.01\right)$. The statistical power of the interaction term for knowledge sharing held the slope coefficient for compensation depends on trust as mediator variable in the model. The increment in the $\mathrm{R}^{2}$ value presented that the moderator had a significant impact on the dependent and independent variable. Thus, moderating role of trust for the compensation and knowledge sharing relation was confirmed. Hence, the fifth hypothesis was accepted. Table 4 presents the scores of moderator variable and their $p$-values which are lower than 0.05 . It represented that trust had a significant influence on the relationship of performance appraisals and knowledge sharing.

Table 4

Model Summary: The Moderating Role of Trust for the Relationship of Performance Appraisals \& Knowledge Sharing

\begin{tabular}{|c|c|c|c|c|c|c|c|c|c|}
\hline \multirow[b]{2}{*}{ Models } & \multirow[b]{2}{*}{$\mathrm{R}$} & \multirow[b]{2}{*}{$\mathrm{R}^{2}$} & \multirow[b]{2}{*}{$\begin{array}{c}\text { Adjusted R } \\
\text { Square }\end{array}$} & \multirow[b]{2}{*}{$\begin{array}{l}\text { Std. Error of } \\
\text { the Estimate }\end{array}$} & \multicolumn{5}{|c|}{ Change Statistics } \\
\hline & & & & & $\mathrm{R}^{2}$ Change & F Change & $\mathrm{df}_{1}$ & $\mathrm{df}_{2}$ & Sig. \\
\hline 1 & $0.14^{\mathrm{a}}$ & 0.02 & 0.22 & 0.76 & 0.02 & 8.43 & 1 & 289 & 0.04 \\
\hline 2 & $0.21^{\mathrm{b}}$ & 0.05 & 0.04 & 0.71 & 0.04 & 14.00 & 1 & 286 & 0.00 \\
\hline 3 & $0.20^{\mathrm{c}}$ & 0.06 & 0.05 & 0.70 & 0.01 & 3.88 & 1 & 285 & 0.03 \\
\hline
\end{tabular}

Model 1 in Table 4 presented a significant relationship between performance appraisals and knowledge sharing $\left(\mathrm{R}^{2}\right.$ change $\left.=0.02\right)$ which showed that performance appraisals had a significant impact on knowledge sharing. Model 2 showed a significance of the estimated coefficient for knowledge sharing variable $\left(\mathrm{R}^{2}\right.$ change $\left.=0.04\right)$. Finally, model 3 represented the significant predictive power of performance appraisals, trust, and interaction term for the two variables in knowledge sharing $\left(\mathrm{R}^{2}\right.$ change $\left.=0.01\right)$. The significance incremental variance of knowledge sharing indicated to the interaction term of the model. The statistical power of interaction term for knowledge sharing held the slope coefficient for performance appraisals depends on predictor variable in the model. The increments for the adjusted $\mathrm{R}^{2}$ value presented the results that the moderator variable had a significant impact on dependent and independent variables. Therefore, sixth hypothesis of study was also confirmed. 


\section{Discussion and Conclusion}

The aim of the present study was to investigate the alternative relationship between training, compensation, performance appraisals, and knowledge sharing with the moderating role of trust. For this purpose, five hypotheses have been developed to be tested in this study and prove that the study either is or is not significant in Pakistan. The current study presented additional support to researcher's opinion that trust strengthened the relationship between human resource practices and knowledge sharing. This study highlighted the importance of trust among employees and in their organization context. Therefore, human resource practices related to knowledge sharing can effectively approve through fulfilling trust. Effective training techniques, fair compensation, and performance appraisals increased the knowledge sharing and trust among coworkers and gave human resource practices and knowledge sharing relationship more strength. The results of moderated regression analysis showed that there were positive significant relationship between independent variables and dependent variable.

The first hypothesis of current study posed training as an effective variable for employees' knowledge sharing in an organization. According to A. Cabrera and E. F. Cabrera (2005), training sessions for employees in different areas facilitated knowledge sharing by creating a common language, building social ties, and increasing interactions. Training plays an important role in sharing knowledge among the employees. Batt (2002) claimed that training enabled the employees to adapt themselves to new environments and helped them build and distribute their new knowledge for retaining continuous learning cycles and performing better.

The results also supported the second hypothesis which stated that the compensation affected knowledge sharing significantly. In many of today's most successful organizations, such kind of compensation system establishes and becomes the vital part of any employees' performance appraisal systems which strongly related to employees' shared information and that's why there is a heavy peer pressure to share ideas, thoughts, and experiences for gaining significant weights (Kanter, 2006). A fair compensation system strongly associated with creation and distribution of knowledge sharing in an organization (Lopez-Cabrales, PérezLuño, \& Cabrera, 2009).

The results indicated that there was a positive association among performance appraisal and knowledge sharing and therefore supported third hypothesis. The $t$-value of performance appraisal was highly significant $(\mathrm{p}<0.05)$ which indicated performance appraisal had a significant impact on knowledge sharing. Some organizations use systematic performance appraisals that specifically relevant to knowledge sharing and it includes regular performance feedback (Jimenez \& Valle, 2013). Currie and Kerin (2010) stated that feedback motivates the employee to share knowledge which can be understood and appreciated in evaluation process. Dyer and Reeves (2006) suggested that the group orientation in performance appraisal can enhance teamwork performances.

In this study, trust was considered as a moderator variable which can strengthen the relationship between independent and dependent variables. Currie and Kerin (2003) stated the importance of trust as a driver of knowledge oriented human resource practices. Interpersonal trust facilitates effective knowledge management process through removing knowledge sharing barriers in an organization (Jimenez \& Valle, 2013). The stepwise regression analysis was used to measure the moderating role of trust. The results showed that trust as moderator variable had 
a significant impact on the relationship of dependant (knowledge sharing) and independent (training, compensation and performance appraisals) variables. The obtained results showed that a significant incremental variance for knowledge sharing is due to addition of trust.

Current study provides important implications for practitioners. An organization that wants to improve knowledge sharing in organization must pay attention to its human resource practices in a trustworthy environment. In particular, organizations should emphasize on training, compensation, and performance appraisals. It is clear that the implementation of these practices will enhance the individuals' learning and the motivation for sharing knowledge within the organizations. In general, this study has practical implications for employees of service sectors and policy makers. The findings of the research indicated that the knowledge management researchers as well as practitioners can help to develop a better understanding of the successful implementation of the knowledge management process. The present study will provide necessary guidelines to understand the issues of knowledge sharing in an organization. The outcomes of this study will be helpful for organizations in order to develop and design compensation and performance appraisals improvement policies and strategies.

In this study, the researcher emphasized only one of the stages of knowledge management process and explored the relationship of human resource practices and knowledge sharing while considering trust as a moderator variable. This study could be conducted to study the effects of human resource management practices on other phases of knowledge sharing processes as well in the future. Furthermore, the effects of human resource management practices on innovation can be assessed where knowledge sharing plays moderating role between independent and dependent variables. Moreover, employees' behavior and their organizational culture can be transformed the relationship between human resource practices and each of the knowledge management processes; however, these variables were not included in this analysis. Furthermore, the scope of this study is limited to service sectors of organizations in just two cities. To check the generalizability of the findings, a similar study could be carried out in other sectors in Pakistan, especially in financial sector, to compare and validate the results.

\section{References}

Albrams, L. C., Cross, R., Lesser, E. \& Levin, D. Z. (2003). Nurturing interpersonal trust in knowledge sharing networks. Academy of Management Executive, 17(4), 64-77.

Allameh, S. M., Zare, S. M., \& Davoodi, S. M. R. (2011). Examining the impact of KM enablers on knowledge management processes. Elsevier Procedia Computer Science, 3, 1211-1223.

Batt, R. (2002). Managing customer services: Human resource practices, quit rates, and sales growth. Academy of Management Journal, 45(3), 587-597.

Bock, G. W., \& Kim, Y. G. (2002). Breaking the myths of rewards: An exploratory study of attitudes about knowledge sharing. Information Resources Management Journal, 15(2), 14-21.

Cabrera, A., \& Cabrera, E. F. (2002). Knowledge sharing dilemmas. Organization Studies, 23(5), 687-710.

Camelo-Ordaz, C., Garcia-Cruz, J., Sousa-Ginel, E., \& Valle-Cabrera, R. (2011). The influence of human resource management on knowledge sharing and innovation in Spain: The mediating role of affective commitment. International Journal of Human Resource Management, 22(7), 1442-1463.

Chen, C. J., \& Huang, J. W. (2011). Strategic human resource practices and innovation performance: The mediating role of knowledge management capacity. Journal of Business Research, 62(1), 104-114.

Chiang, H. H., Han, T. S., \& Chuang, J. S. (2011). The relationship between high-commitment HRM and knowledge-sharing behavior and its mediators. International Journal of Manpower, 32(5/6), 604-622. 
Cohen, J., \& Cohen, P. (1983). Applied multiple regression correlation analysis for the behavioral sciences $\left(^{\text {nd }}\right.$ ed.). Hillsdale, NJ: Lawrence Erlbaum.

Collins, C. J., \& Smith, K. G. (2009). Knowledge exchange and combination: The role of human resource practices in the performance of high-technology firms. Academy of Management Journal, 49(3), 544-560.

Currie, G., \& Kerrin, M. (2010). Human resource management and knowledge management: Enhancing knowledge sharing in a pharmaceutical company. International Journal of Human Resource Management, 14(6), 1027-1045.

Dyer, L., \& Reeves, T. (2006). Human resource strategies and firm performance: What do we know and where do we need to go? The International Journal of Human Resource Management, 6(3), 656-670.

Edvardsson, I. R. (2008). HRM and knowledge management. Employee Relations, 30(5), 553-561.

Goodman, P. S., \& Darr, E. D. (2000). Computer-aided systems and communities: Mechanisms for organizational learning in distributed environments. MIS Quarterly, 22(4), 417-440.

Grimshaw, D., \& Miozzo, M. (2009). New human resource management practices in knowledge-intensive business service firms: The case of outsourcing with staff transfer. Human Relations, 62(10), 1521-1550.

Hall, H., \& Goody, M. (2007). KM, culture, and compromise: Interventions to promote knowledge sharing supported by technology in corporate environments. Journal of Information Science, 33(2), 181-188.

Hassan, M., Toylan, N. V., Semerciöz, F., \& Aksel, I. (2012). Interpersonal trust and its role in organizations. International Business Research, 5(8), 33-39.

Holste, J. S., \& Fields, D. (2010). Trust and tacit knowledge sharing and use. Journal of Knowledge Management, 14(1), 128140.

Ipe, M. (2003). Knowledge sharing in organizations: A conceptual framework. Human Resource Development Review, 2(4), $337-359$.

Jimenez, D. J., \& Valle, R. S. (2013). Studying the effect of HRM practices on the knowledge management process. Personnel Review, 42(1), 28-49.

Kanter, J. (1999). Knowledge management, practically speaking. Information Systems Management, 16(4), 7-15.

Liu, N.C., \& Liu, M. S. (2011). Human resource practices and individual knowledge-sharing behavior: An empirical study for Taiwanese R \& D professionals. International Journal of Human Resource Management, 22(4), 981-997.

Lopez-Cabrales, A., Pérez-Luño, A., \& Cabrera, R. V. (2009). Knowledge as a mediator between HRM practices and innovative activity. Human Resource Management, 48(4), 485-503.

McAllister, D. J. (1995). Affect- and cognition-based trust as foundations for interpersonal cooperation in organizations. Academy of Management Journal, 38(1), 24-59.

Nonaka, I. (1994). A dynamic theory of organizational knowledge creation. Organization Science, 5(1), 14-37.

Nunnally, J. C. (1978). Psychometric theory (2 $2^{\text {nd }}$ ed.). New York: McGraw-Hill.

Pareek, U., \& Purohit, S. (2010). Training instruments in human resource development and OD ( $3^{\text {rd }}$ ed.). New Dehli: Tata McGraw Hill.

Renzl, B. (2008). Trust in management and knowledge sharing: The mediating effects of fear and knowledge documentation. Omega, 36(2), 206-220.

Saeed, T., Ahmad, M., Anis-Ul-Haque, M., \& Chaudhry, A. (2010). Knowledge management practices: Role of organizational culture. Proceedings of ASBBS Annual Conference, Las Vegas, 17(1) 127-136.

Selvarajan, T. T., \& Cloninger, P. A. (2012). Can performance appraisals motivate employees to improve performance? A Mexican study. The International Journal of Human Resource Management, 23(15), 3063-3084.

Staples, D. \& Webster, J. (2008). Exploring the effects of trust, task interdependence and virtualness on knowledge sharing in teams. Information Systems Journal, 18, 617-640.

Warr, P. B. (1990). Decision latitude, job demands, and employee well-being. Work \& Stress, 4(4), $285-294$.

Wasko, M. M., \& Faraj, S. (2005). Why should I share? Examining social capital and knowledge contribution in electronic networks of practice. MIS Quarterly, 29(1), 35-57.

Yang, C., \& Chen, L. C. (2007). Can organizational knowledge capabilities affect knowledge sharing behavior? Journal of Information Science, 33(1), 95-109. 